\title{
Topical Effect of Aloe Vera Gel versus Silver Nanoparticles on Socket Healing in Methylprednisolone Treated Albino Rats
}

\author{
Original \\ Article \\ Asmaa Shaker Elkasas ${ }^{1}$,Heba Mohammed Eltokhey', Amal Mohammad Ezzat \\ Abd Elhamid, ${ }^{1,2}$ and Gihan Shehatah Albastawisy Hassan ${ }^{1}$
}

Department of Oral Biology, Faculty of Dentistry, ${ }^{1}$ Tanta University, ${ }^{2} 6$ October University, Egypt

\begin{abstract}
Background: Methylprednisolone causes a delay in dental extraction wound healing. There are finite data for the effect of Aloe Vera gel and silver nanoparticles gel on tooth socket healing in methylprednisolone treated Albino rats.

Purpose: To evaluate the topical effect of using Aloe Vera gel versus silver nanoparticles gel on socket healing in methylprednisolone treated Albino rats.

Materials and Methods: Adult male Albino rats were divided into three groups. Group I (control group); Subgroup A and Subgroup B: received intramuscular injection of sterile normal saline and methylprednisolone acetate $(0.2 \mathrm{mg} / \mathrm{kg}, 3 \mathrm{times} /$ week for 5 weeks) respectively. After this period, lower right first molars were extracted. Group II and Group III were as group IB while, the sockets were filled with $92 \%$ Aloe Vera and silver nanoparticles gel respectively. Rats were sacrificed at day 7 and day 14. Rats' sockets were processed for histological and scanning electron microscopic examination.

Results: Group IB showed a delay in socket healing. Group II showed the socket was filled with osteoid matrix at day 7. Then the socket was nearly filled with thick intercommunicating lamellar bone trabeculae with wide bone marrow spaces at day 14. Surprisingly, Group III revealed thin intercommunicating woven bone spicules at day 7. At day 14, the socket became nearly obliterated with thick intercommunicating bone trabeculae with formation of numerous primary osteons with small bone marrow spaces.

Conclusion: MP had a marked osteoporotic effect on rat mandible and delayed the socket healing process. Aloe Vera gel and AgNps gel improved the socket healing in MP treated Albino rats.
\end{abstract}

Received: 07 May 2020, Accepted: 14 July 2020

Key Words: Aloe; methylprednisolone (MP), silver nanoparticles (AgNps), tooth socket healing.

Corresponding Author: Asmaa Shaker Elkasas, MSc, Department of Oral Biology, Faculty of Dentistry, Tanta University, Egypt, Tel.: +20 1096089635, E-mail: asmaashaker285@gmail.com

ISSN: 1110-0559, Vol. 44, No.2

\section{INTRODUCTION}

Methylprednisolone (MP) is a synthetic Glucocorticoid (GC) drug. It is usually used for the medication of rheumatic diseases, allergic reactions, inflammatory skin disorders and cerebral edema such as psoriasis and eczema ${ }^{[1]}$. Severe side effects of GCs, including detrimental effects on the skeleton, have been reported. The most imperative side effect of GCs is glucocorticoid induced osteoporosis $(\mathrm{GIO})^{[2]}$. Also, GCs cause a delay in dental extraction wound healing in rats ${ }^{[3]}$.

Tooth extraction is the removal of a tooth from the alveolus in the alveolar bone leaving a socket ${ }^{[4]}$. After tooth removal, the blood fills the socket then a platelet aggregation occurred to forms a clot. Subsequently, the dental socket is rapidly colonized by granulation tissue; which resides of neo-vascular tissues, inflammatory cells and erythrocytes. The later stage is termed the provisional matrix, where the mesenchymal cells are organized into a dense network, within the collagen fibers and vessels. Afterwards, fingerlike formation of immature bone within the matrix starts. This immature bone is consecutively remodeled into compact and spongy bone ${ }^{[5]}$. Thus, the alveolar bone healing process after tooth extraction is determined as an example of the intramembranous bone healing process ${ }^{[6]}$.
Aloe Vera is a perennial succulent plant that its gel is achieved from the parenchymatous leaf cells or pulp. It contains proteins, amino acids, lipids, vitamins, inorganic compounds, enzymes, small organic compounds and different carbohydrates ${ }^{[7]}$. It affords a more mature granulation tissue which could accelerate wound healing ${ }^{[8]}$. In addition, it blocks the release of prostaglandin and thromboxane A2 from arachidonic acid which decrease wound inflammation ${ }^{[9]}$. Significantly, Aloe Vera gel can be used in the treatment of oral disturbances such as gingivitis, mouth sore, dental pulp inflammation and in accelerating the healing process of extraction socket ${ }^{[10]}$.

AgNps of the Nano-size range $(1-100 \mathrm{~nm})$ in diameter can be produced. They have anti-microbial activities without overt side effects ${ }^{[1]]}$. Moreover, they display remarkable anti-inflammatory and new unusual biological properties on the cells. They increase the rate of wound closure by promoting the proliferation and migration of keratinocytes. They stimulate the differentiation of fibroblasts into myofibroblasts that increase wound contraction $^{[12]}$. Moreover, Zhang et al.$^{[13]}$ found that AgNps promoted the proliferation and osteogenesis of mesenchymal stem cells 
(MSCs) and improved bone fracture healing through using a mouse femoral fracture model.

Although there have been several studies on Aloe Vera and $\mathrm{AgNps}$, the present work is the first to test the effect of Aloe Vera gel and AgNps gel on socket healing in MP treated albino rats. Specifically, newly formed bone mass was evaluated by light (LM), scanning electron microscope (SEM), histomorphometric measurement and statistical analysis.

\section{AIM OF OUR WORK}

This study was conducted to evaluate the topical effect of using Aloe Vera gel versus Silver Nanoparticles gel on socket healing in methylprednisolone treated Albino Rats.

\section{MATERIALS AND METHODS}

\section{Materials}

Aloe Vera gel $92 \%$ was obtained from SigmaAldrich, St Louis, MO, USA. AgNPs gel, its concentration is $107 \mathrm{ppm}$ with average size of $25 \pm 5 \mathrm{~nm}$, obtained from NanoTech Egypt for Photo-Electronics Communication Center, El-Wahaat Road, Dream Land City, Entrance 3, City of 6 October, Al Giza, Egypt. Methylprednisolone acetate, suspension. Trade name is depo-Medrol $40 \mathrm{mg}$ Suspension for injection, which obtained from Pfizer Company, Egypt.

\section{Animals}

A total 32 adult male Albino rats aged between 8-10 weeks (200-250 grams) were used in this study. The animals were obtained and housed in the animal house center at Anatomy and Histology department, Faculty of Veterinary, Kafr-Elshiekh University, Egypt. The animals were housed for two weeks individually in a temperature-controlled room $\left(22^{\circ} \mathrm{C}\right)$ with a 12 -hours light-dark cycle and had free access to food and water ${ }^{[14]}$. All experiments were reviewed and approved by the guidelines for the responsible use of animals in research as a part of scientific research ethics recommendation of ethical committee at Faculty of Dentistry, Tanta University.

\section{Experimental design}

The animals were randomly divided into 3 groups; Group I (Control group) (12 Rats) that was subdivided into;

Subgroup A (-ve control): 6 rats in this subgroup received IM injection of sterile normal saline $(0.2 \mathrm{mg} / \mathrm{kg}, 3$ times/ week for 5 weeks).

Subgroup B (+ve control): 6 rats in this subgroup received IM injection of methylprednisolone acetate $(0.2$ $\mathrm{mg} / \mathrm{kg}, 3$ times/week for 5 weeks $^{[15]}$.

After this period, lower right first molars were extracted. Group II (10 Rats) as group I subgroup B (IB) then the sockets were filled with $92 \%$ Aloe Vera gel immediately after extraction.
Group III (10 Rats) as group IB then the sockets were filled with AgNps gel immediately after extraction. AgNp has been prepared by chemical reduction method as reported by ${ }^{[16]}$.

\section{Methods}

All rats of all groups were anaesthetized then the lower right first molars were extracted. The sockets of group I were sutured then left to heal by themselves without any treatment. The sockets of group II were dropped with $92 \%$ Aloe Vera gel and AgNps gel in group III. Then the sockets were sutured to stabilize the gel. 6 rats from group I \& 5 rats from group II\&III were sacrificed by cervical decapitation at day 7 and day 14 .

After sacrification, the right half of the mandible containing the socket was dissected out and processed for subsequent examination using LM (H\&E) and SEM examination to evaluate the healing.

Light Microscopic examination (Qualitative method) (H\&E): After rinsing the specimen in sterile water, the sample of the socket have been fixed in $10 \%$ formalin for 28 hours then demineralized in $10 \%$ neutral-buffered Ethylenediaminetetraacetic Acid (EDTA) using magnetic stirrer at 410c for 2 weeks. The EDTA solution was changed every other day. The samples endpoint of decalcification was confirmed radiographically. The samples were washed in tap water over night, dehydrated in ascending grade of ethanol series, cleared in xylene and then embedded in low melting point paraffin wax.

Serial sections corresponding to the area of the first molars of $5-\mu \mathrm{m}$ thickness were sectioned mesio-distally along the molars in an apico-coronal vertical plane at the socket area. Sections were cut using microtome (Leica microtome RM2245) then mounted on commercially available positively charged glass slides. The central-most section was selected based on the position of the adjacent roots. Deparaffinized sections were stained for 3-10 minutes with Coles haematoxylin and washed with tap water. Then they were stained with $1 \%$ eosin 1-2 minutes. Inflammatory infiltrates and new bone formation in the slides were observed under LM (Leica DM500) ${ }^{[17]}$.

Scanning Electron Microscopic Examination (SEM) was carried out in Faculty of Medicine, Tanta University and Faculty of Science, Alexandria University. The sample of approximately $1 \mathrm{~cm}^{3}$ in dimension in the area of the socket has been prepared then the sockets were left intact or trimmed in buccolingual direction, then immersed immediately in fixative solution of SEM. Each sample was trimmed to average dimensions of 10x10x5 $\mathrm{mm}^{3}$. The specimens were examined using JSM 5200 LV SEM and photographed by Orion 6.60 software package contain camera drivers.

Histomorphometric measurements using image $\mathrm{j}$ software were done to measure the percentage of new bone formation in the extraction socket in different groups at the two observation periods. Then the data were analyzed using the SPSS (version 22). The average of surface area of newly 
formed bone mass in different standardized depths of the block of the rat alveolus had been determined. Three slices were cut longitudinally from each block then stained with H\&E. The photographs of these slices examined by LM under 10x objective lenses. A rectangle with standardized dimensions was drawn on the desired area to be measured.

The surface area of this selected region was measured by choosing Region of interest (ROI) manager, from tools from analyze and the measurements were recorded to be considered the total surface area. The surface area occupied by the marrow spaces and other tissue spaces was selected with the wand tracing tool and the measurement was recorded. The two measurements were subtracted to obtain the surface area occupied by the bone only, and the percentage of new bone to the total surface area was calculated. The measurements from the three photographs were recorded and their mean was calculated for each of the three sections obtained from three specimens.

\section{RESULTS}

\section{Clinical results}

The weight of MP treated rats decreased from about $250 \mathrm{gm}$, used at the start of injections, to range of 150-180 gm after 5 weeks. While the weights of saline treated rats increased normally with growth.

In postoperative period, about $25 \%$ of MP treated rats died during the postoperative period while all saline treated rats survived.

\section{LM and SEM examination at day 7}

LM examination of Group IA illustrated partially obliterated socket with moderate sized intercommunicating central newly formed woven bone spicules that were surrounded with fibrous connective tissue. Higher magnification of the apical third showed osteoclasts inside their Howship's lacunae, primary osteon lined by continuous plump osteoblasts and multiple reversal lines (Figure 1A,B). Whereas, Group IB: revealed partially filled socket with granulation tissue with scanty newly formed thin separated woven bone spicules dispersed through enormous remnants of granulation tissue. Multiple osteoclasts inside their Howship's lacunae were obvious at the base of the socket. Higher magnification of the apical third showed separated woven bone spicules that contained large and irregularly distributed osteocytes and were lined by continuous raw of plump osteoblasts (Figure 2A,B)

Group II showed osteoid matrix at the base and sides of the socket along with newly formed fine separated woven bone spicules at the apical third of the socket. Higher magnification of the apical third illustrated few delicate and nearly intercommunicating woven bone spicules. It was lined by continuous plump osteoblasts and contained large and irregularly distributed osteocytes (Figure 3A,B).

Group III exhibited thin intercommunicating woven bone spicules separated by fibrous connective tissue filling the base of the socket. Higher magnification of the apical third illustrated the woven bone spicules enclosed high density of large and irregularly distributed osteocytes and were lined by plump osteoblasts (Figure 4A,B).

SEM examination of Group IA showed partially obliterated sockets with granulation tissue. Bone spicules were noticed at the central region of the cervical half of the socket. Higher magnification of the bone spicules showed typical globular pattern of calcification (Figure 5A,B). Group IB showed unobliterated sockets with apical localized dense granulation tissue. Higher magnification of the apical third showed wide numerous deep anastomosing cracks with collagen fibers exposure. The crack was surrounded by several Howship's lacunae (Figure 6A,B).

Group II: SEM examination showed partially obliterated sockets with central bone formation. The base of the socket comprised obvious newly formed bone spicules with crystal aggregation and area of bone resorption manifested as irregular resorbed wall of the alveolus. Higher magnification of the newly formed bone spicules at the base of the socket showed crystal aggregation (Figure 7A,B)

Group III: SEM examination illustrated the sockets filled with granulation tissue. Higher magnification of the apical third showed area of active bone formation contained hydroxyapatite crystals embedded in partially calcified collagen fibers. Multiple osteoblasts surrounding the newly formed bone were obvious (Figure 8A,B)

\section{LM and SEM examination at day 14}

LM examination of Group IA showed nearly filled socket with thick intercommunicating lamellar bone trabeculae surrounding large bone marrow spaces with large congested blood vessels. The trabeculae contained primary osteons and were surrounded by large marrow spaces with large congested blood vessels. The trabeculae were lined by continuous plump osteoblasts and contain smaller and more regularly distributed osteocytes (Figure 9A,B)

Group IB revealed partially filled socket with granulation tissue with scanty newly formed thin separated woven bone spicules dispersed through the socket. The base of the socket showed multiple osteoclasts inside their Howship's lacunae. Higher magnification of the apical third showed reversal lines separate the woven bone from the lamellar bone. The separated woven bone spicules contained large and irregularly distributed osteocytes and were lined by a continuous raw of plump osteoblasts (Figure 10A,B)

Group II showed nearly filled socket with thick intercommunicating lamellar bone trabeculae with primary osteons formation. Wide bone marrow spaces were noticed in between with fine remnants of granulation tissue cervically. Higher magnification of the apical third of the socket revealed small and regularly distributed osteocytes and surrounded by continuous plump osteoblasts (Figure 11A,B)

Group III exhibited nearly filled socket with thick intercommunicating bone trabeculae with formation of numerous primary osteons that surround small bone marrow 
spaces. The bone trabeculae contained the largest proportion of Haversian canals. Higher magnification of the apical third of the socket illustrated several primary osteons lined by plump osteoblasts and contained large and moderate regularly distributed osteocytes (Figure 12A,B)

SEM examination of Group IA showed completely obliterated socket. Higher magnification of the socket showed central smooth bone trabeculae extended from the apical to the cervical third of the socket and separated by connective tissue which was covered by bone crystals (Figure 13A,B). Group IB revealed not yet obliterated socket. The wall of the socket revealed separated irregular eroded socket wall with exposed collagen fibers that were studded by few fine bone crystals. At higher magnification, exposed collagen fibers were studded by few fine bone crystals (Figure 14A,B).

Group II revealed narrowed sockets due to lateral bone formation with narrow cracks in between them. Higher magnification of the lateral wall of the socket showed the new bone trabeculae with numerous collagen fibers coated by hydroxyapatite crystals (Figure 15A,B). Group III showed completely obliterated socket with bone trabeculae separated by small marrow spaces. While, the other socket was incompletely obliterated with lateral bone formation. Higher magnification of the lateral wall of the socket exhibited collagen fibers coated with fewer hydroxyapatite crystals as compared with group II (Figure 16A,B).

\section{Statistical analysis}

The new bone surface area formed in the healing socket was analyzed (Table 1). The greatest mean average of new bone formation in the socket was recorded in group III, with the least value obtained in group IB. ANOVA test revealed very highly significant difference between groups (IB, II and III) but there was no statistical significance between group IA. The difference between each two groups was statistically significant, except the difference between group IB and group II at day 7 (Figure 17).
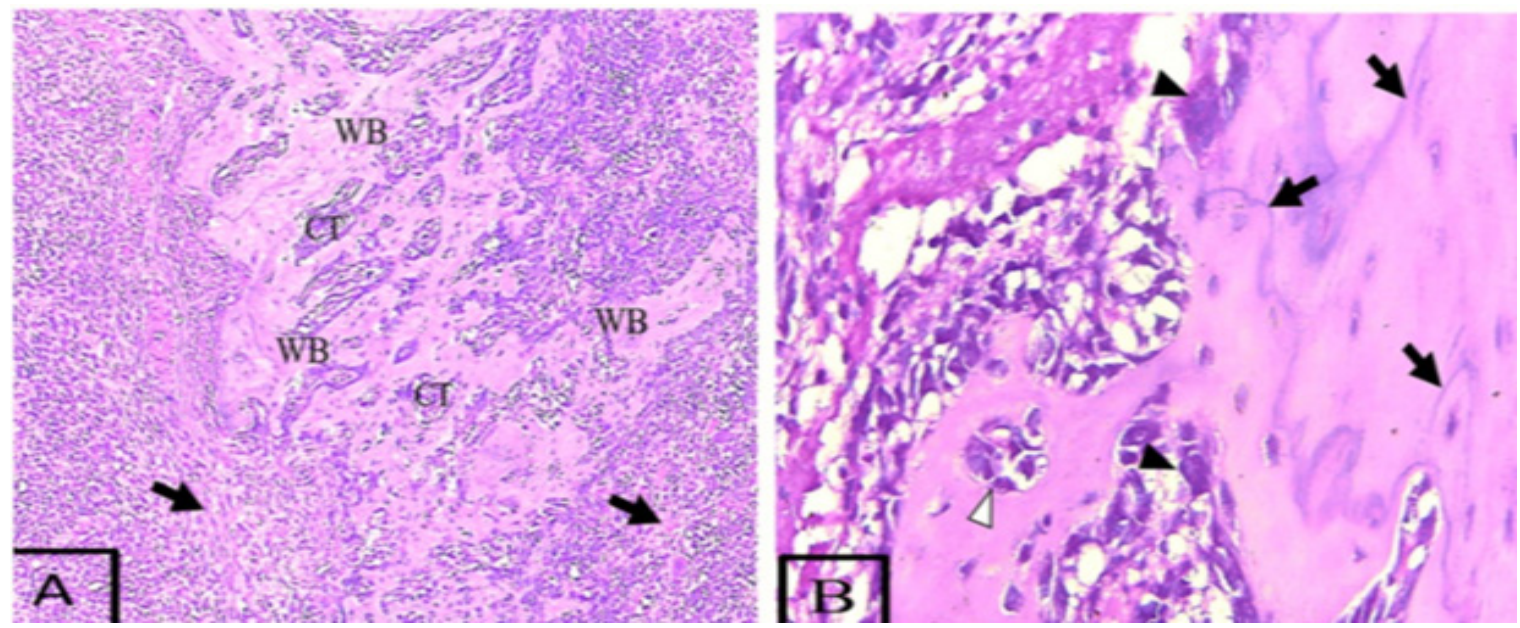

Fig. 1: Photographs of the sockets of Group IA at day 7 showing; (A) Partially obliterated socket with centrally newly formed moderate sized intercommunicating woven bone spicules (WB) surrounding fibrous connective tissue (CT). Arrows; osteoid matrix. (B) Higher magnification of the apical third of the same group showing osteoclasts inside their Howship's lacunae (black arrow heads) and primary osteon lined by continuous plump osteoblasts (white arrow heads). Notice, multiple reversal lines (arrows). (H\&E orig. mag., (A) $\times 10,(B) \times 40)$

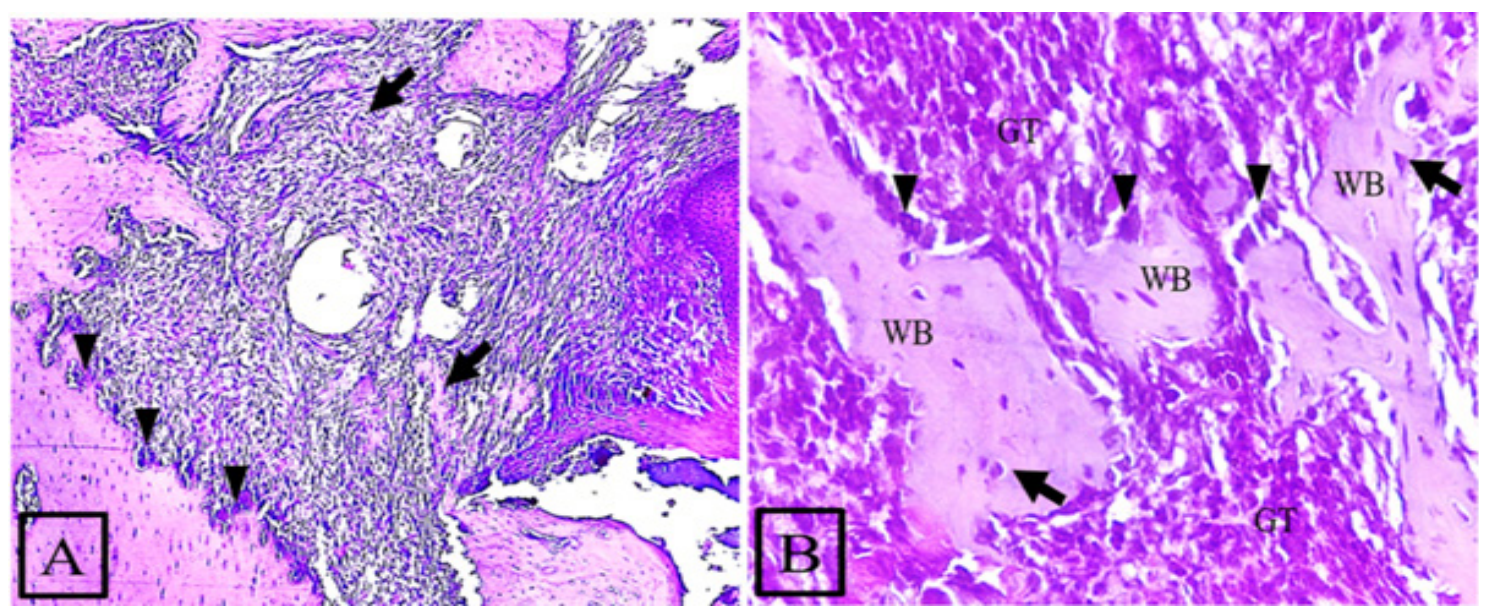

Fig. 2: Photographs of the sockets of Group IB at day 7 showing; (A) partially filled socket with granulation tissue with scanty newly formed thin separated woven bone spicules dispersed through the socket (arrows). Notice, the base of the socket with advanced moth-eaten appearance (multiple osteoclasts inside their Howship's lacunae) (arrow heads). (B) Higher magnification of the apical third of the same group showing separated woven bone spicules (WB) that contain large and irregularly distributed osteocytes (arrows) and lined by continuous raw of plump osteoblasts (arrow heads). GT; enormous remnants of granulation tissue. (H\&E orig. mag., $(\mathrm{A}) \times 10,(\mathrm{~B}) \times 40$ ) 


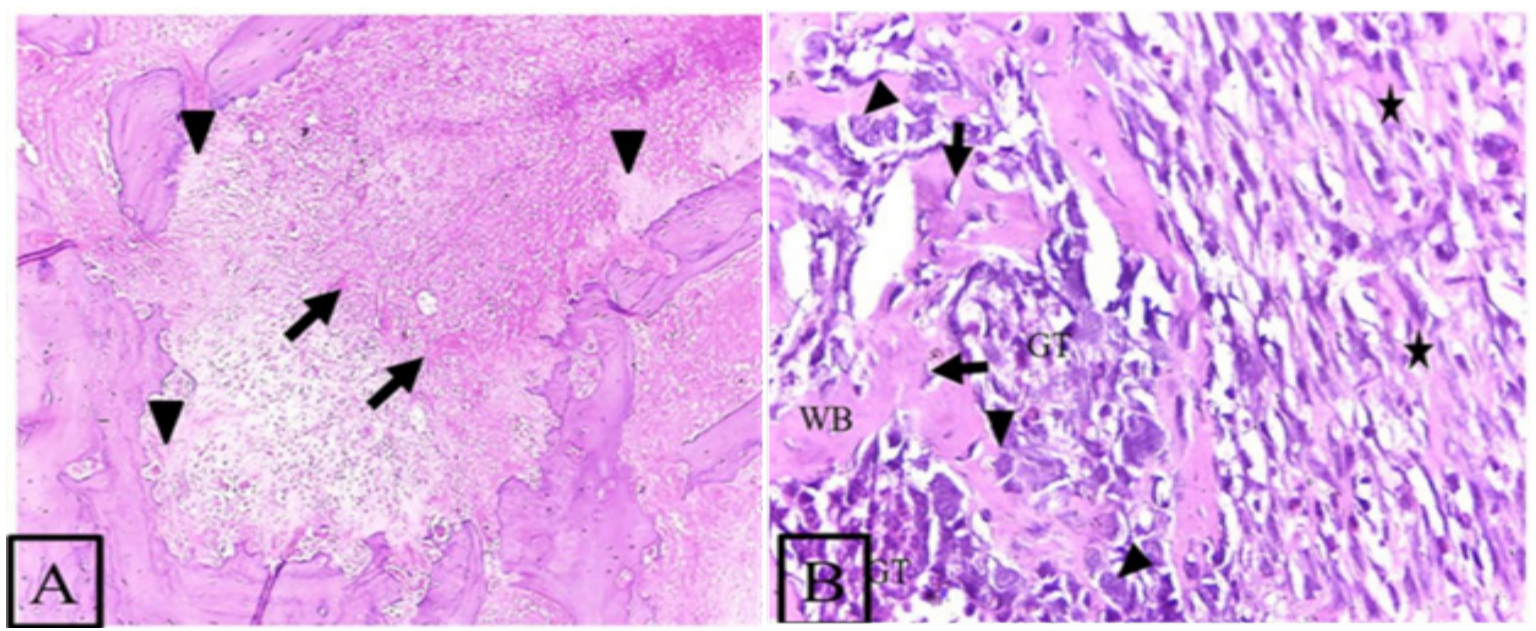

Fig. 3: Photographs of the sockets of Group II at day 7 showing; (A) The socket was filled with osteoid matrix at the base and sides of the socket (arrow heads) with newly formed fine separated woven bone spicules at the apical third of the socket (arrows). (B) Higher magnification of the apical third of the same group showing few, delicate and nearly intercommunicating woven bone spicules (WB). These spicules contain large and irregularly distributed osteocytes (arrows) and are lined by continuous plump osteoblasts (arrow heads). (H\&E orig. mag., (A) $\times 10,(\mathrm{~B}) \times 40)$
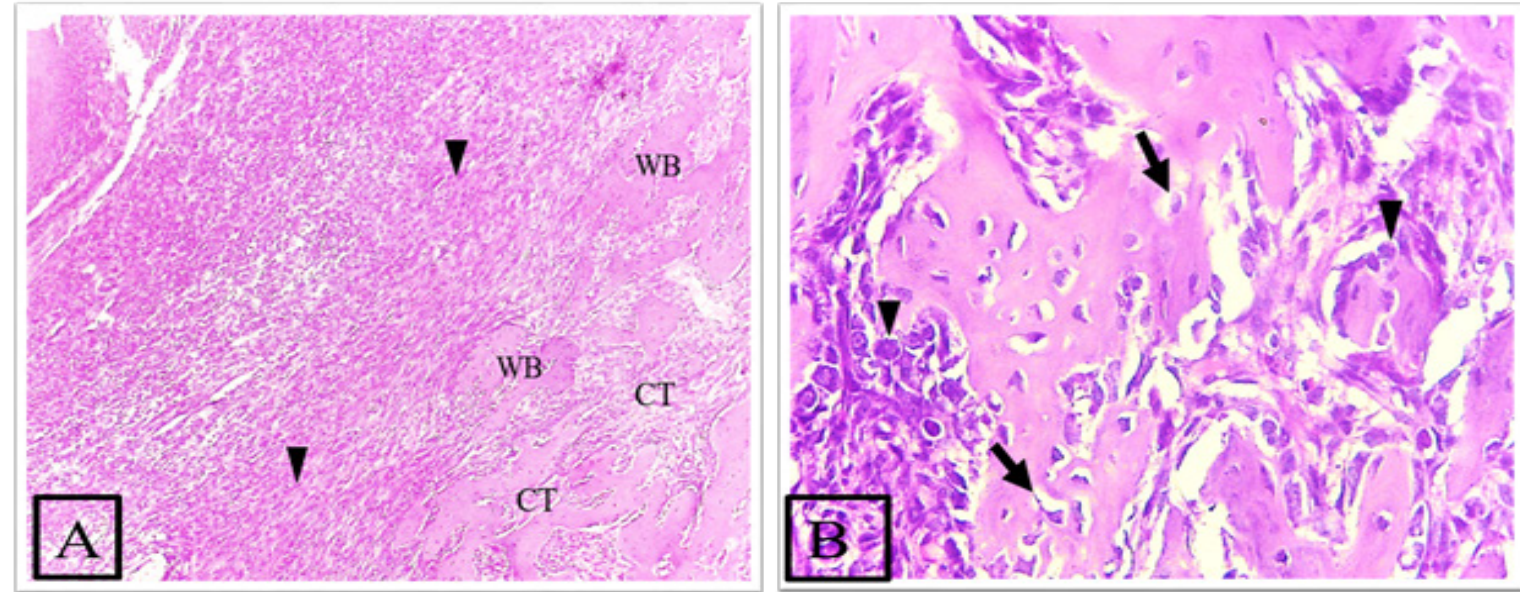

Fig. 4: Photographs of the sockets of Group III at day 7 showing; (A) Thin intercommunicating woven bone spicules (WB) separated by fibrous connective tissue (CT) filling the base of the socket. Osteoid matrix is observed at the middle third (arrow heads). (B) Higher magnification of the apical third of the same group showing woven bone spicules with large and irregularly distributed osteocytes (arrows) and lined by plump osteoblasts (arrow heads). (H\&E orig. mag., $(\mathrm{A}) \times 10,(\mathrm{~B}) \times 40)$
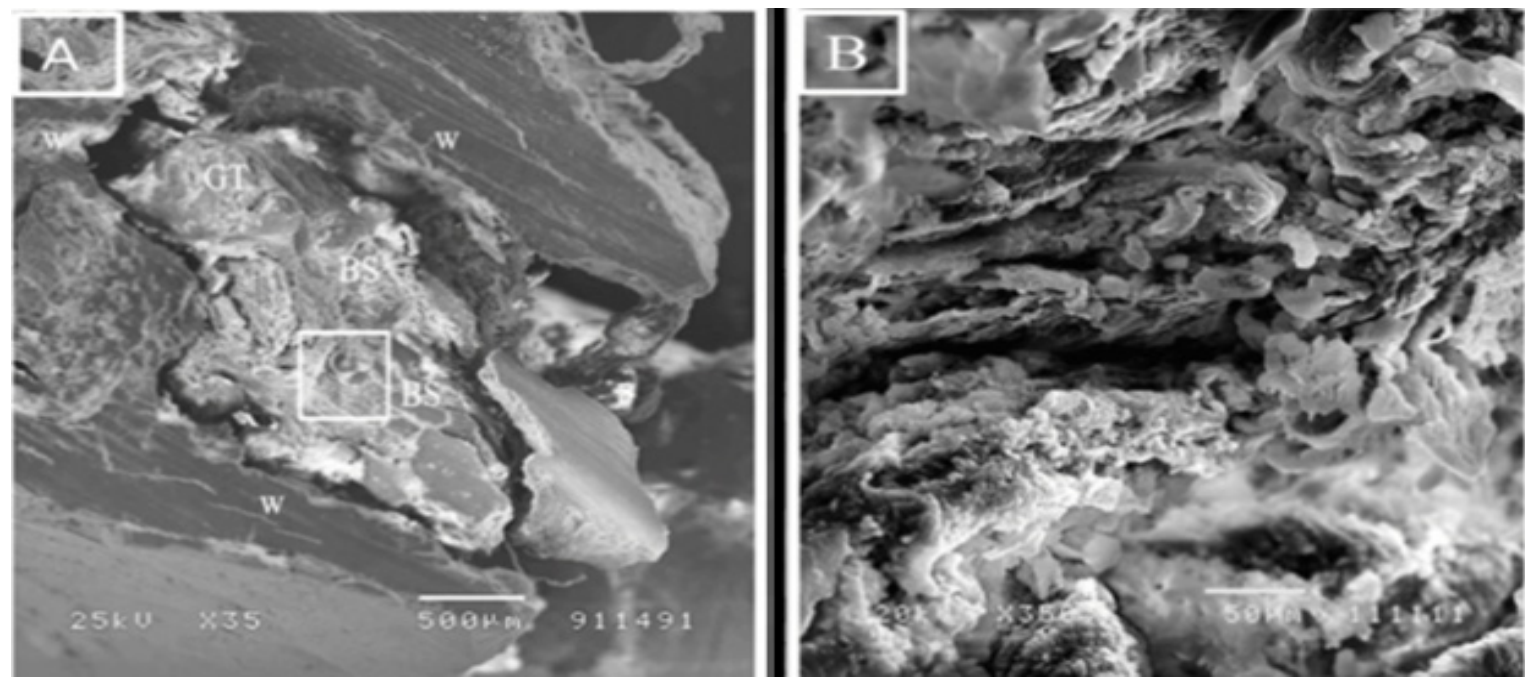

Fig. 5: SEM photographs of the sockets of Group IA at day 7 showing; (A) longitudinal section of partially obliterated socket. Bone spicules is noticed at the central region of the cervical half of the socket (BS) within the granulation tissue $(\mathrm{GT})$. W; wall of the socket. $(\times 35)$. (B) Higher magnification of the framed inset in the previous figure showing typical globular pattern of calcification. $(\times 350)$. 

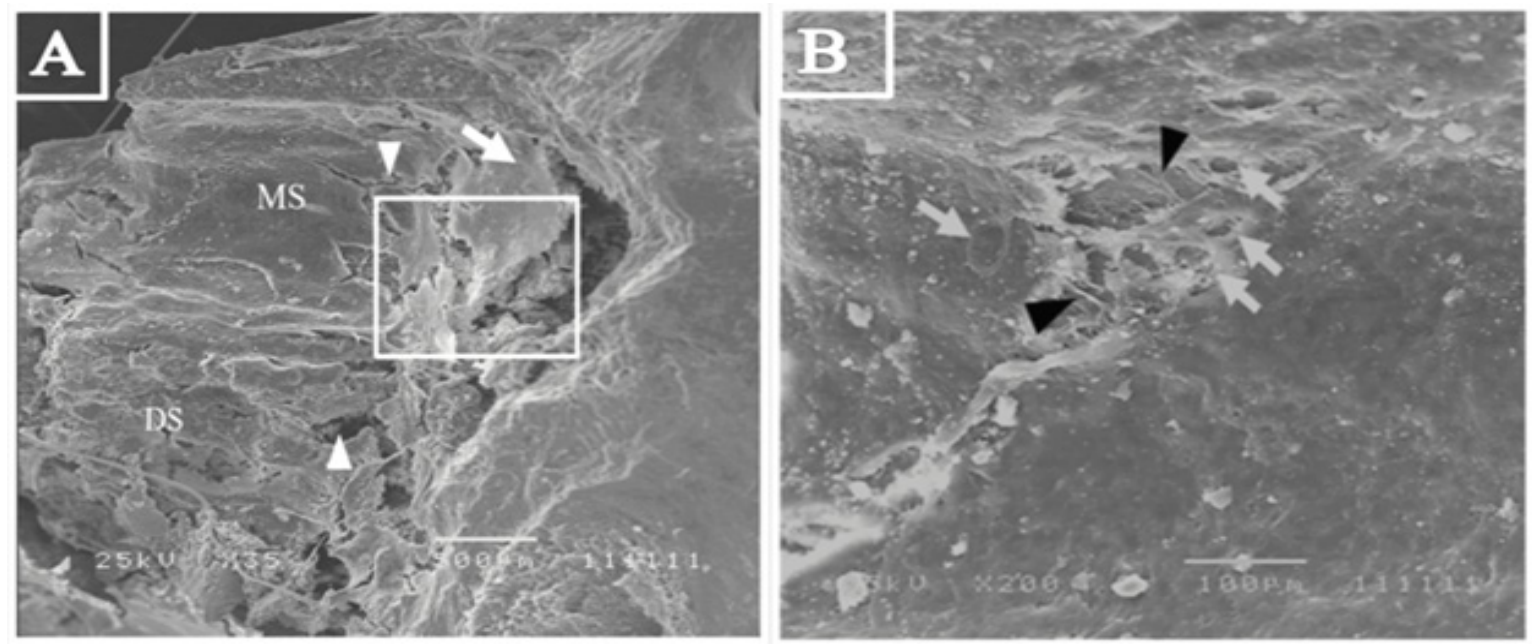

Fig. 6: SEM photographs of the sockets of Group IB at day 7 showing; (A) longitudinal section of unobliterated mesial and distal socket (MS\&DS). Mesia and distal socket wall exhibit numerous deep anastomosing cracks (arrow heads) with apical localized dense granulation tissue in the mesial socket (arrow). ( $\times 35$ ). (D) Higher magnification of the framed inset showing wide separation of the bone exposing collagen fibers (arrow heads). There are several Howship's lacunae surrounding the crack (arrows). $(\times 200)$
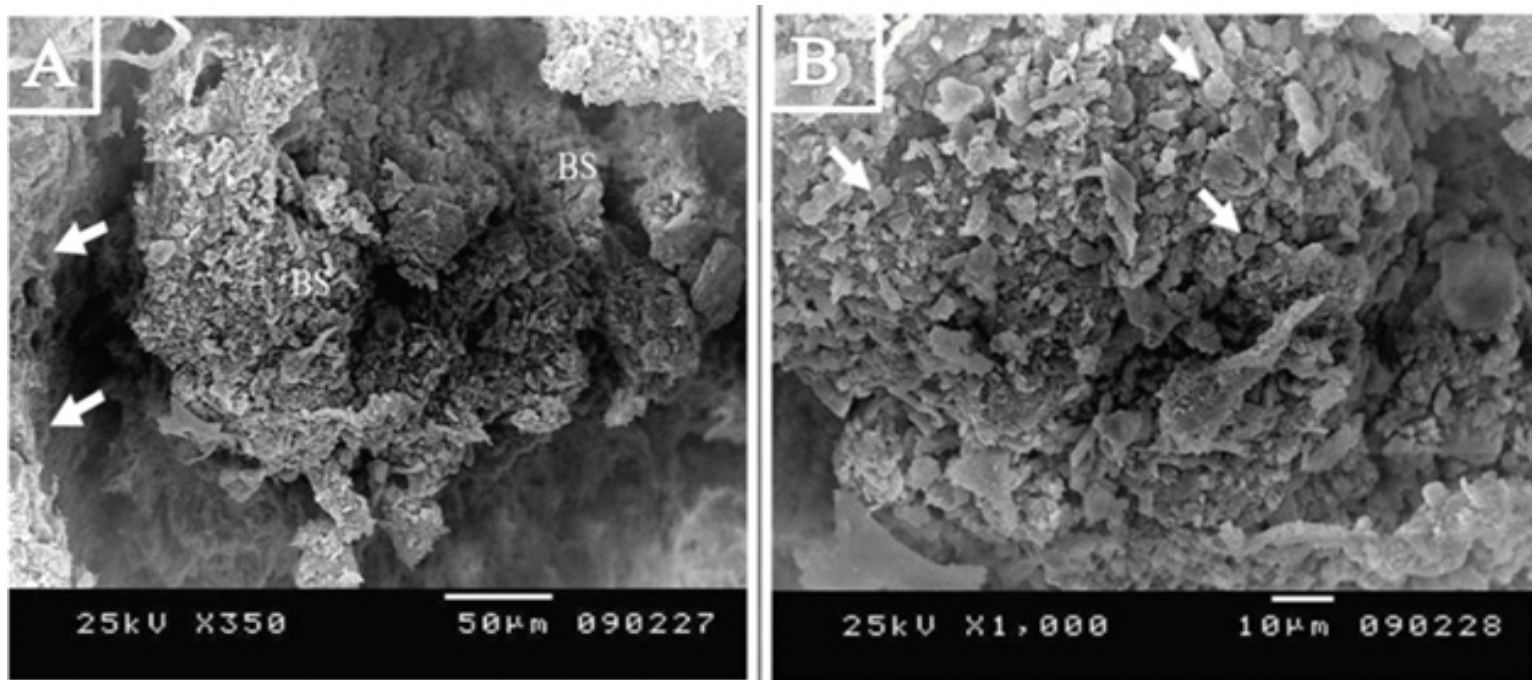

Fig. 7: SEM photographs of the sockets of Group II at day 7 showing; (A) top view of partially obliterated sockets with contrasting areas of bone formation with obvious newly formed bone spicules at the base of the socket (BS) and areas of bone resorption which manifested as irregular resorbed wall of the alveolus (arrows). ( $\times 350)$. (B) Higher magnification of the newly formed bone spicule at the base of the socket showing crystal aggregation (arrows). $(\times 1000)$
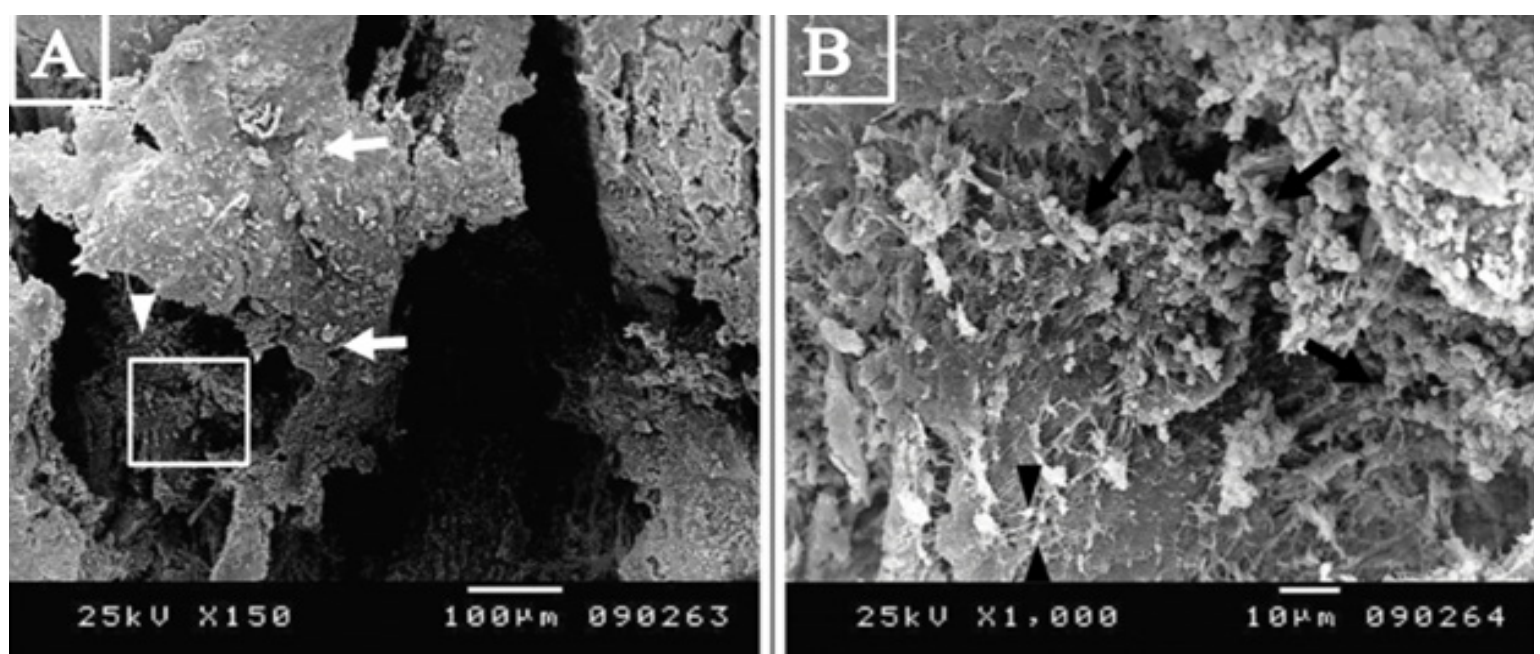

Fig. 8: SEM photographs of the sockets of Group III at day 7 showing; (A) the socket filled with granulation tissue (arrows) with apical new bone formation (arrow head). $(\times 150)$ (B) Higher magnification of the framed inset in the previous figure showing area of active bone formation contains hydroxyapatite crystals embedded in partially calcified collagen fibers (arrows). There are obvious osteoblasts (arrow heads). $(\times 1000)$ 

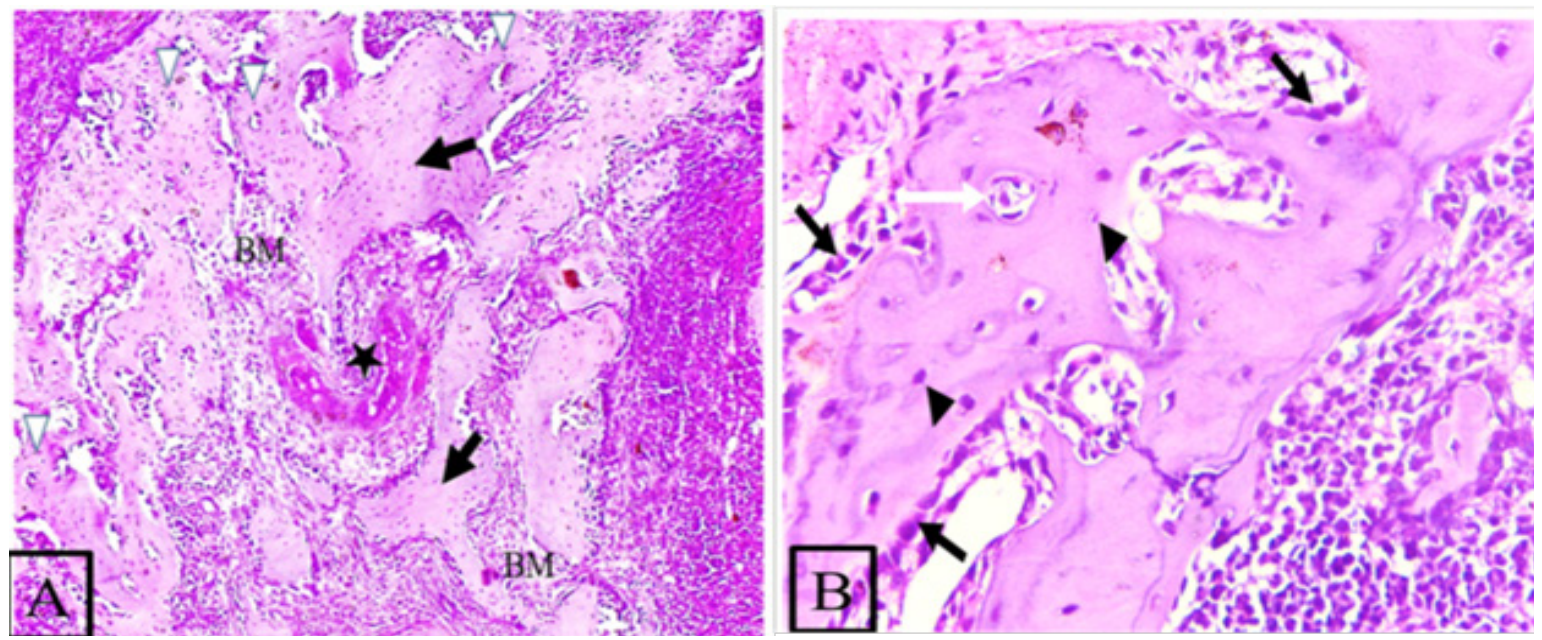

Fig. 9: Photographs of the sockets of Group IA at day 14 showing; (A) The majority of the socket is filled with thick lamellar bone trabeculae (arrows) surround large bone marrow spaces (BM) with large congested blood vessels (star). Haversian canals of primary osteons filling most of the socket are detected (white arrow heads). (B) Higher magnification of the apical third of the socket of the same group showing trabeculae lined by continuous plump osteoblasts (black arrows) and contain smaller and more regularly distributed osteocytes (arrow heads). Notice, Haversian canals of primary osteons (white arrows). (H\&E orig. mag., (A) $\times 10,(B) \times 40)$

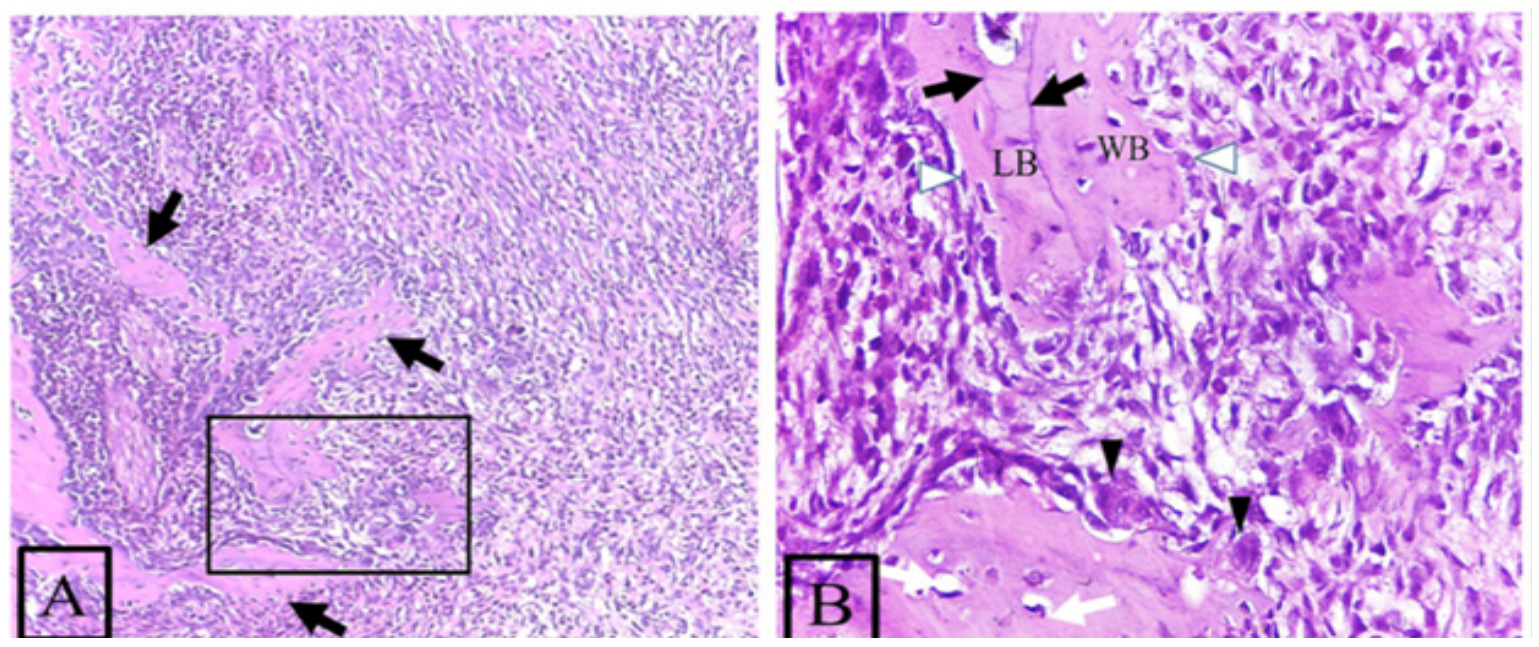

Fig. 10: Photographs of the sockets of Group IB at day 14 showing; (A) partially filled socket with granulation tissue with scanty newly formed thin separated woven bone spicules dispersed through the socket (arrows). Notice, the base of the socket with advanced moth eaten appearance (multiple osteoclasts inside their Howship's lacunae) (arrow heads).. (B) Higher magnification of the framed inset (apical third) showing separated woven bone spicules (WB) that contain large and irregularly distributed osteocytes (arrows) and lined by continuous raw of plump osteoblasts (arrow heads). GT; enormous remnants of granulation tissue. (H\&E orig. mag., (A) $\times 10$, (B) $\times 40$ )
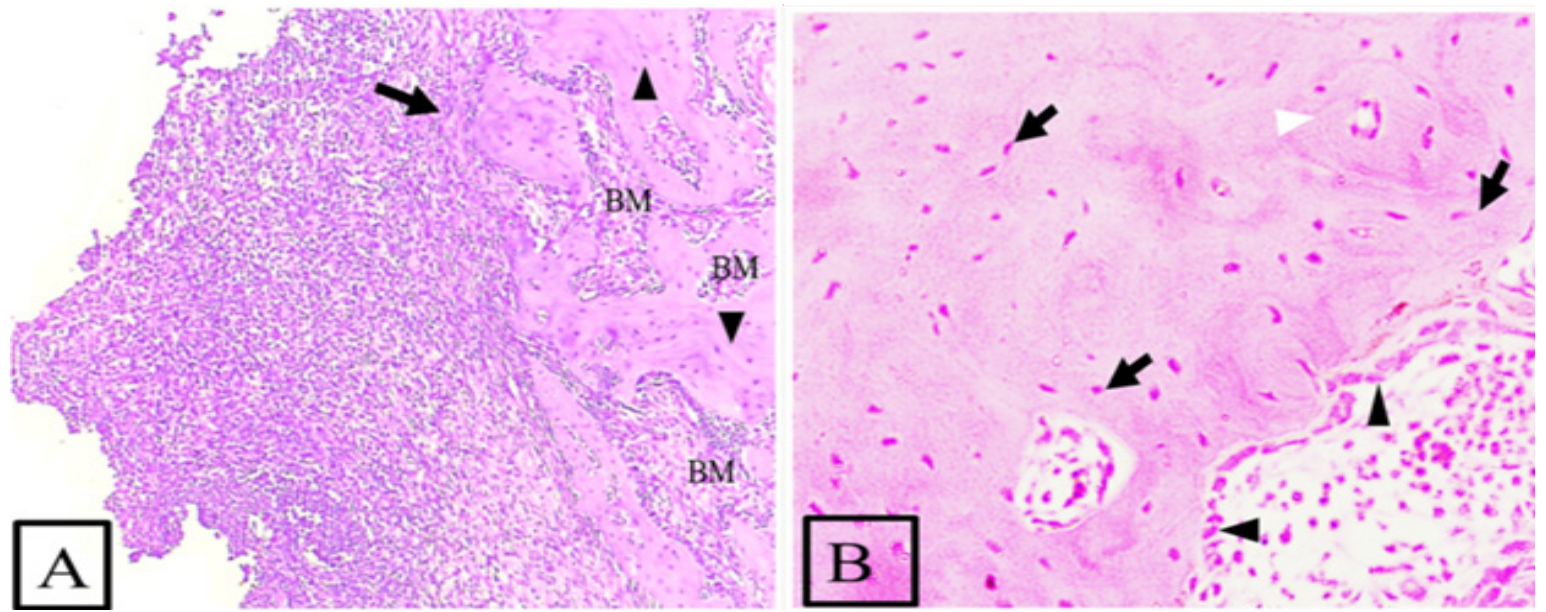

Fig. 11: Photographs of the sockets of Group II at day 14 showing; (A) nearly filled socket with thick lamellar bone trabeculae that are projecting and spanning the socket with wide bone marrow spaces inbetween (BM). Notice, osteoid matrix (arrow). (B) Higher magnification of the apical third of the same group showing small and regularly distributed osteocytes (arrows) and surrounded by continuous plump osteoblasts (black arrow heads). Notice, the beginning of primary osteon formation (white arrow head). (H\&E orig. mag., (A) $\times 10,(B) \times 40)$ 


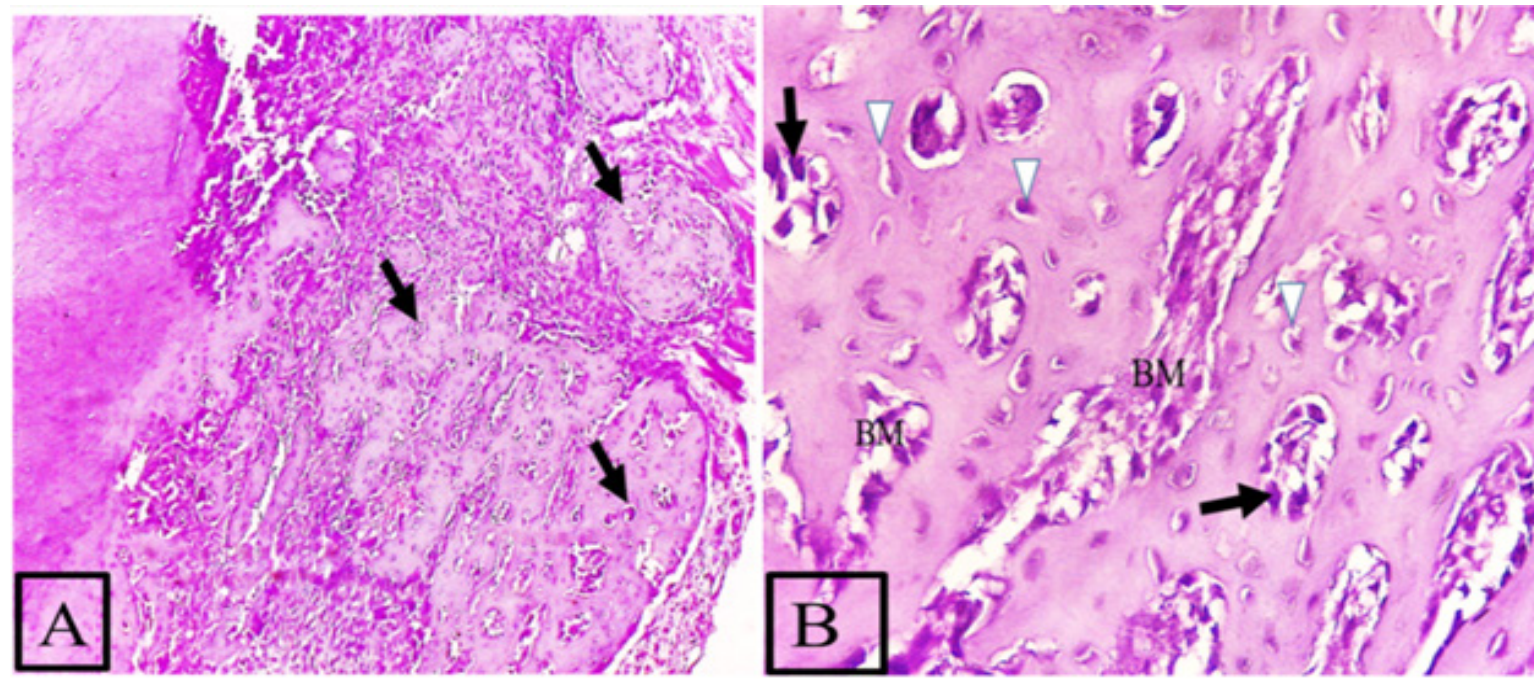

Fig. 12: Photographs of the sockets of Group III at day 14 showing; (A) The socket nearly filled with thick intercommunicating bone trabeculae with formation of numerous primary osteons (arrows). (B) Higher magnification of the apical third of the same group showing several Haversian canals lined by plump osteoblasts (primary osteons). Notice, small bone marrow spaces (BM). Notice, large and moderate regularly distributed osteocytes (arrow heads). (H\&E orig. mag., (A) $\times 10,(B) \times 40)$
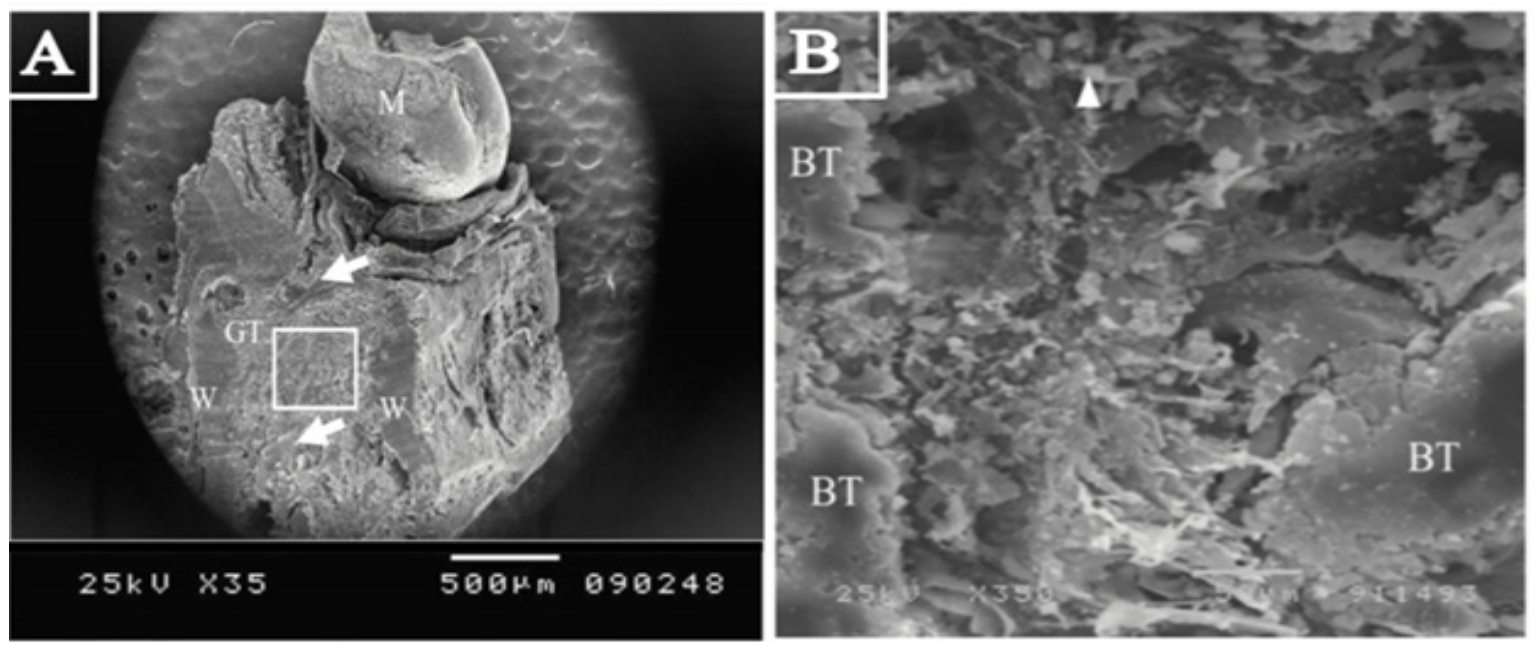

Fig. 13: SEM photographs of the sockets of Group IA at day14 showing; (A) longitudinal section of completely obliterated socket. Also, central bone trabeculae extend from apical third to cervical third of the socket (arrows) within the granulation tissue (GT) can be noticed. M: mandibular second molar. W; wall of the socket. $(\times 35)$ (B) Higher magnification of the framed inset showing smooth bone trabeculae (BT). Also, areas of connective tissue covered by bone crystals can be noticed (arrow heads). $(\times 350)$
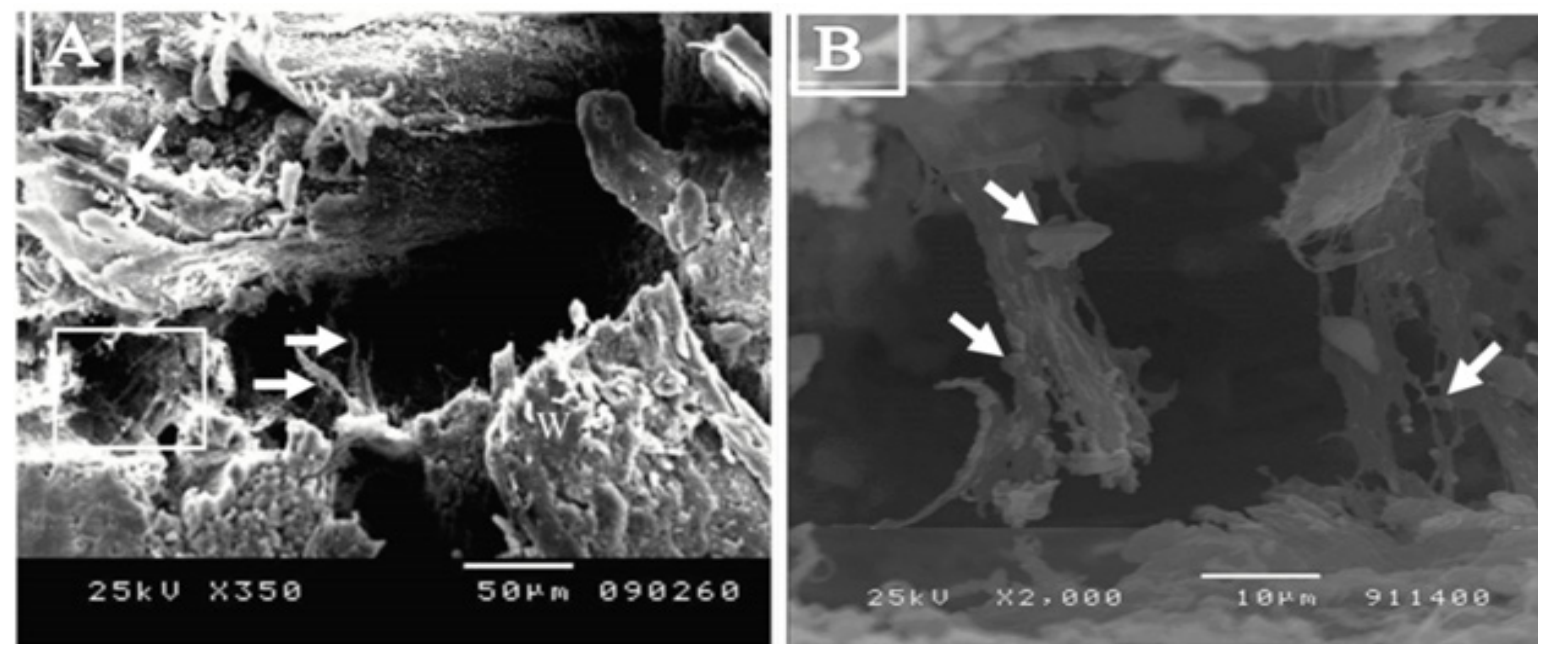

Fig. 14: SEM photographs of the sockets of Group IB at day14 showing; (A) not yet obliterated socket with separated irregular eroded socket wall (W) with exposed collagen fibers (arrows). $(\times 350)$. (B) Higher magnification of the framed inset in the previous figure showing exposed collagen fibers that were studded by few fine bone crystals (arrows). $(\times 2000)$ 


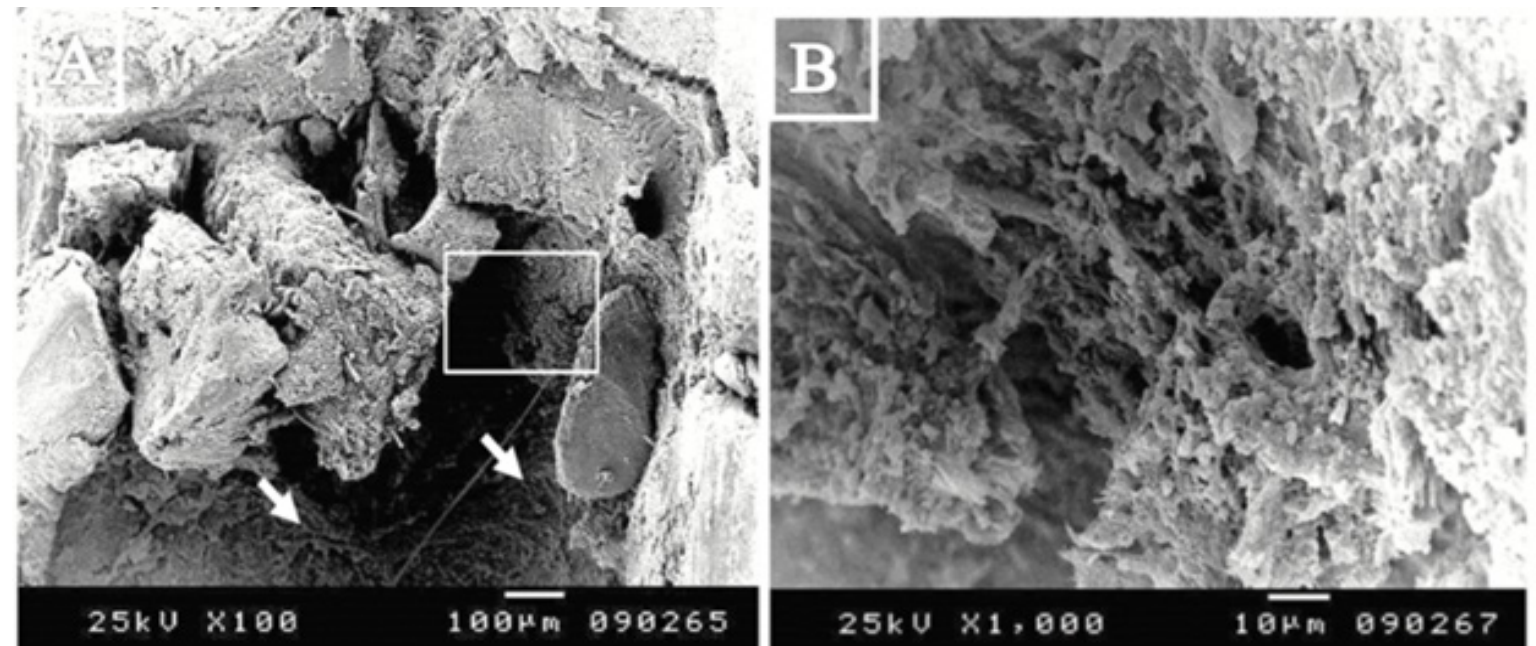

Fig. 15: SEM photographs of the sockets of Group II at day 14 showing; (A) narrowing of the socket due to lateral bone formation (arrows). $(\times 100)$ (B) Higher magnification of the new bone trabeculae showing numerous collagen fibers coated by hydroxyapatite crystals. $(\times 1000)$

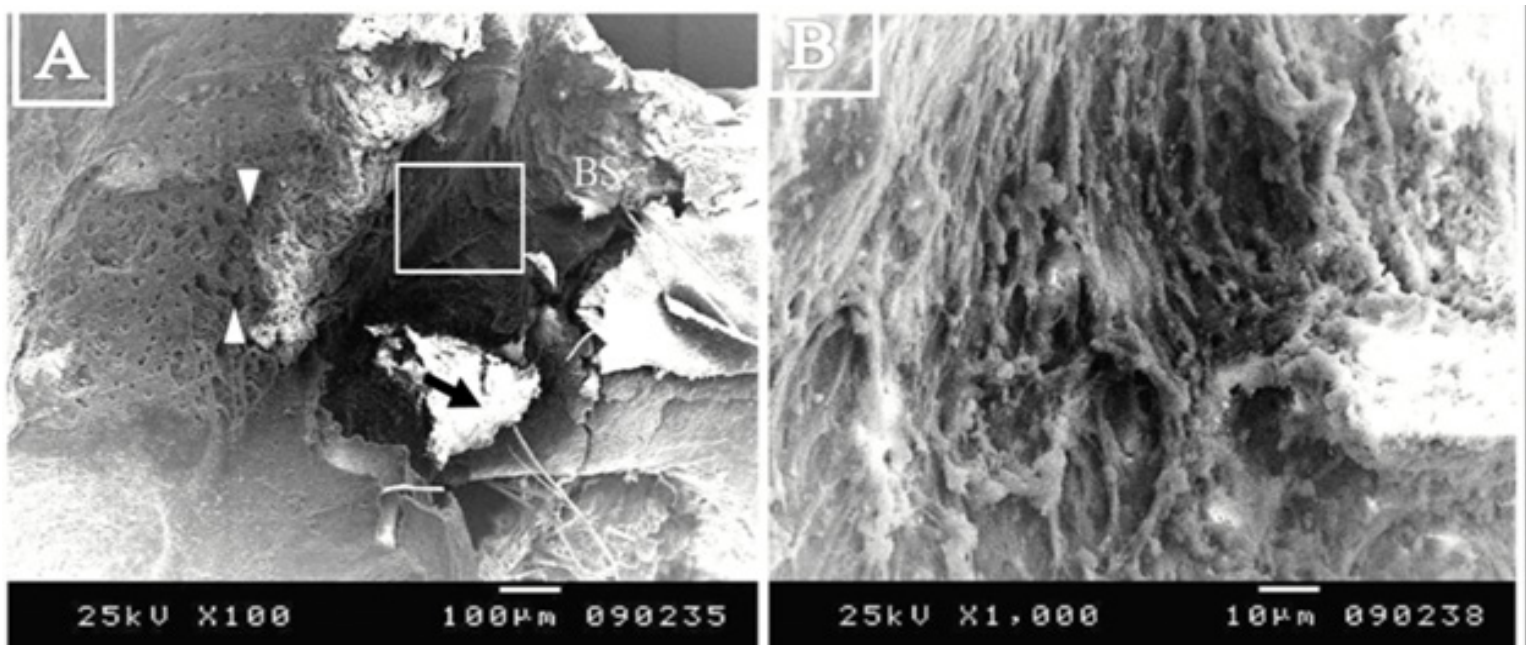

Fig. 16: SEM photographs of the sockets of Group III at day 14 showing; (A) completely obliterated distal socket with bone separated by small marrow spaces (arrow heads) while mesial socket is incompletely operated with lateral bone formation (black arrow). ( $\times 100)$ (B) Higher magnification of the framed inset in the previous figure showing collagen fibers coated with hydroxyapatite crystals. $(\times 1000)$

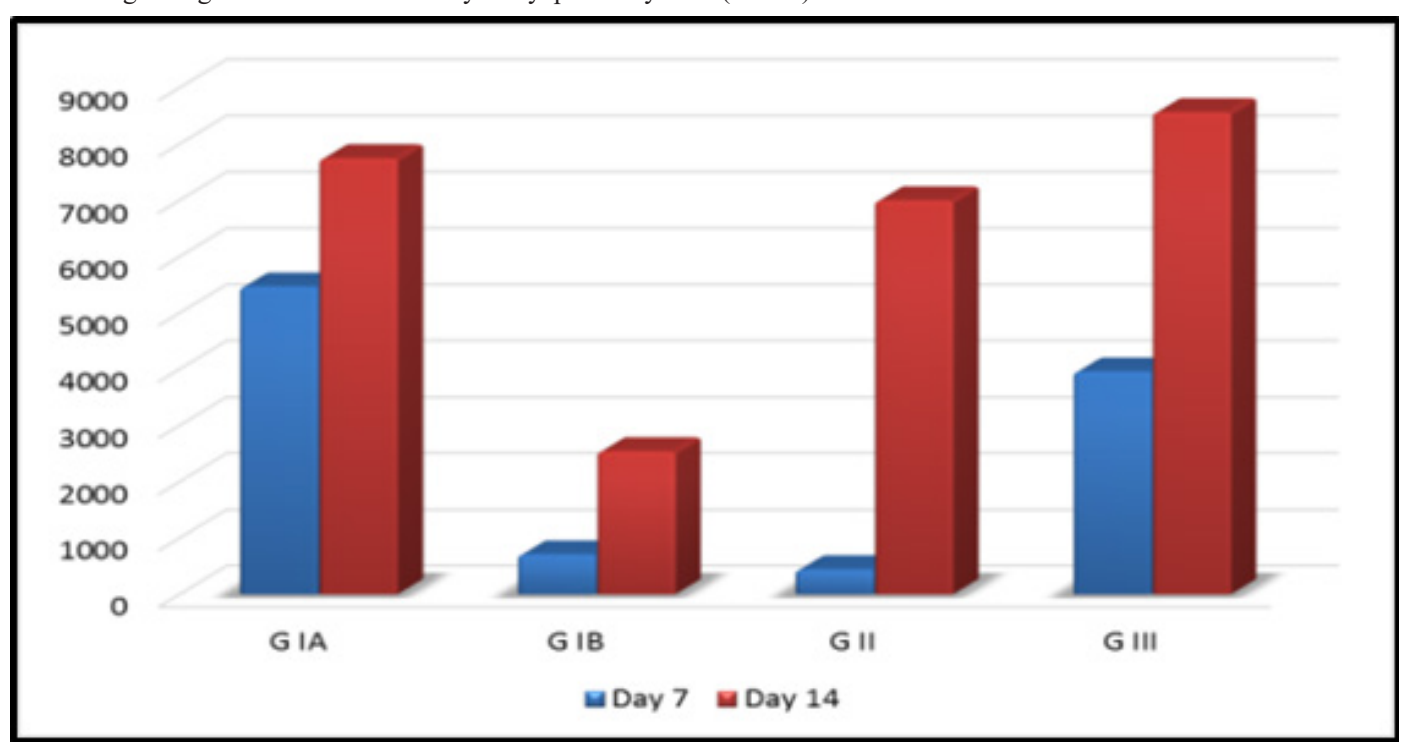

Fig. 17: Bar chart shows the percentage of newly formed bone occupying the extraction socket of all groups at day 7 and day 14. (day 7=blue column, day 14=red column) 
Table 1: Independent t-test of the mean percentage of new bone formation in the two different periods (day $7 \&$ day 14 ) in all groups

\begin{tabular}{cccccc}
\hline & & Range & Mean \pm S. D & t. test & value \\
\hline \multirow{2}{*}{ G1A } & day 7 & $1018-11659$ & $5464.00 \pm 3337.96$ & 3.015 & 0.101 \\
& day 14 & $5406-11482$ & $7742.40 \pm 2465.29$ & $705.00 \pm 376.31$ & 22.237 \\
G1B & day 7 & $185-1462$ & $2538.00 \pm 1170.19$ & 52.024 \\
& day 14 & $690-4325$ & $438.80 \pm 331.24$ & $0.001^{*}$ \\
G II & day 7 & $154-1223$ & $6994.70 \pm 2855.13$ & 12.539 \\
& day 14 & $2351-10820$ & $3953.10 \pm 3132.39$ & $0.001^{*}$ \\
\hline
\end{tabular}

t: Student t-test

p: $\mathrm{p}$ value for comparing between the studied groups

*: Statistically significant at $p \leq 0.05$

\section{DISCUSSION}

Socket healing was used as a form for the study of bone formation in rats. Moreover, alveolar wound healing following tooth extraction was stated to be a sensitive index of bone damage under different experimental conditions. Interestingly, it must be taken in consideration that ossification phases in socket healing in rats completes within 28 days that corresponds to 64 days in humans ${ }^{[18]}$. Moreover, osteoporosis was established in male Albino rats by receiving MP acetate (as intramuscular injection $0.2 \mathrm{mg} /$ $\mathrm{kg}, 3$ times/ week for 5 weeks) to induce GIO. This dose was similar to that of Lelovas et al. ${ }^{[15]}$ and Samir et al. ${ }^{[19]}$.

LM examination of the socket healing of group IB on day 7 revealed delayed socket healing with decreased bone formation. It appeared as thin separated newly formed woven bone spicules spreading through enormous remnants of granulation tissue within the socket. This was corresponding to Hars and Massler ${ }^{[20]}$ who demonstrated a delayed bone formation in the socket with topically applied cortisone and prednisolone on a blood clot until 10 days after extraction. This was also coincided with previous investigations which studied the effects of GCs on long bone healing models ${ }^{[3,21]}$. On contrary, Li et al ${ }^{[14]}$ who studied the healing of mandibular defect in adult male Sprague-Dawley rats which were subjected to daily subcutaneous injection of dexamethasone sodium phosphate $(0.4 \mathrm{mg} / \mathrm{kg} / 24 \mathrm{~h})$. They demonstrated that there were no significant influences on the healing status at late stages of healing between day 10 and day 17 and the trabecular bone formed rapidly in the dexamethasone treated group.

On SEM, the wall of the socket demonstrated numerous deep anastomosing cracks with wide separation of the bone exposing collagen fibers. This result was confirmed by Rollo et al. ${ }^{[22]}$ who made a study on osteoporotic lumbar vertebrae. They found cracks and fractures with greater irregularity, trabecular thinning, poor connectivity and deterioration of microarchitecture.

The histological examination of group IB at day 14 established that socket healing was delayed than all other groups. It showed incompletely obliterated socket when compared with other groups. There were very thin woven bone spicules bathed in the granulation tissue at the base of the socket. It was in agreement with Shen et al ${ }^{[23]}$ They reported that new osteoblasts were hardly seen in osteoporotic bone and if present have little function and scattered sparsely. In addition, this interpretation was supported by Martinelli et al. ${ }^{[24]}$ and Kim et al. ${ }^{[25]}$ who found that chronic GC therapy caused reduction in bone remodeling that establishes mostly due to direct effect of GCs on osteoblasts.

SEM of the same group at day 14 exhibited irregular and eroded wall of the socket with multiple resorption lacunae. This was in accordance with Shen et al. ${ }^{[23]}$. They found that postmenopausal osteoporotic women bone trabeculae appeared to be thin, broken, tapered and perforated. In addition, a number of resorption lacunae of various shapes were seen on the surface of the trabeculae. This was correlated to our result of thin bone spicules with exposed collagen fibers which were studded with few fine bone crystals.

Histological examination of group II at day 7 revealed osteoid matrix which was continuous with the base and sides of the socket along with few fine separated woven bone spicules were shown at the apical third. The lower degree of mineralization of osteoid bone may be interpretated by the fact that GCs decrease calcium level through decreasing absorption from the gastrointestinal tract and decreasing its reabsorption from renal tubules ${ }^{[26]}$. Moreover, aloe Vera enhance the rate of bone formation and did not permit enough time for secondary mineralization ${ }^{[27]}$.

At day 14 in the same group, there was a substantial ingrowth of bone trabeculae that nearly filled the socket. It means that Aloe Vera gel improved the growth and maturation of the bone spicules. It was coincident with Boonyagul et al. ${ }^{[28]}$ who examined the effect of an acemannan treated sponge in the healing of extraction socket of mandibular incisors of male Sprague Dawley rats. They reported that at day 7 , there were lots of osteoid matrix and after day 14 , denser and thicker bone trabeculae were revealed (deviation from normal degree of mineralization).

Corroborating observations by Al-Hijazi et al. ${ }^{[29]}$ who used $2 \mathrm{~mm}$ femur bone defect in male Swiss rats. At day 7 , they noticed osteoid tissue formation, at the periphery of the bone defect site of the experimental groups. Furthermore, 
at day 14, the experimental group showed bone trabeculae filled approximately the whole defect. Moreover, Jansisyanont et al..$^{[30]}$ observed that acemannan increased the bone density. In addition, they reported that tooth socket healing of mandibular partial bony impacted third molars was significantly greater five times than control at 3-months post-surgery in (18-24 years old human). Moreover, no dry sockets were experienced in Aloe Vera treated group.

SEM of group II at day 14, there were bone trabeculae with numerous collagen fibers coated by crystals. This collagen formation represents the end of differentiation and gives site for mineral precipitation ${ }^{[31]}$. This was in agreement with Beniash et al. ${ }^{[32]}$ and Georgiadiset et al. ${ }^{[33]}$. They found that mineralized collagen fibrils were formed by the combination of collagen fibrils and hydroxyapatite mineral crystals.

Histological study of the healed socket at day 7, there were obvious thin intercommunicating woven bone spicules continuous with the base of the socket. This was in agreement with $\mathrm{Ng}$ et al. ${ }^{\left[{ }^{[3]}\right]}$ and Solchaga et al. ${ }^{[35]}$. They claimed that AgNps stimulated proliferation and differentiation of fibroblasts. Fibroblasts emit growth factors, which stimulate the proliferation of MSCs, stimulate callus formation and accelerate healing of fracture bone. In addition, Jung et $a l^{[36]}$ during the reparative phase, exhibited that AgNps encouraged MSCs to migrate from both ends of the fracture bone to the fracture site differentiate into osteoblast, which form woven bone. As well as, Zhang et al.$^{[13]}$ evaluated the effect of AgNps gel on promoted osteogenesis and improved bone fracture healing in mouse. They detected osteoid matrix in the fracture area at day 7 , and it is a similar finding at the present group.

SEM of group III at day 7 revealed newly formed bone with area of active bone formation containing hydroxyapatite crystals embedded in partially calcified collagen fibers. Moreover, there were obvious osteoblasts surrounding the newly formed bone spicules. These results were coincided with the LM results.

Afterward, at day 14, thick bone trabeculae with obvious numerous primary osteons formation which were composed of Haversian canals that were lined by plump osteoblasts and were surrounded by 1-2 lamellae. Moreover, small bone marrow spaces in between the bone trabeculae were prominent. The presence of $\mathrm{AgNps}$ has a key role in this improvement of socket healing that was explained by Keleştemur et al.$^{[37]}$. They stated that surface modification of AgNps was to improve the biocompatibility of nanoparticles by delaying the release of silver ions and minimizing their toxic effect on tissues. As a result, a regulated inflammatory response and enhanced proliferative phase of wound healing via rapid fibroblasts and collagen deposition was detected. In addition, AgNps gel was used to increase the socket healing in treated rats due to its high antimicrobial activity (major application in medicine) ${ }^{[38]}$.

Fortunately, statistical analysis confirmed that group II and III had a significant increase in the percentages of new bone formation compared with group IB. It indicated that AgNps gel and Aloe Vera gel improved the socket healing through advancement of MSCs and osteogenesis and reversed the action of MP on bone. Whereas, the delay of the socket healing process by MP depends on its inhibitory effects on osteogenic differentiation and maturation of MSCs cells into osteoblasts, resulting in a decreased number of osteoblasts.

\section{CONCLUSION}

AgNps gel resulted in better socket healing at early periods as compared with Aloe Vera gel. The bone formation in Aloe Vera group improved obviously at day 14. While at day 7 the socket was filled with osteoid tissue and this result was better than MP treated group.

\section{ACKNOWLEDGEMENT}

Foremost, I would like to express my deepest gratitude to the members of Department of Oral Biology, Faculty of Dentistry, Tanta University. All funding source is from my account.

\section{CONFLICT OF INTERESTS}

There are no conflicts of interest.

\section{REFERANCES}

1. Huang X, Du Y-Z, Yuan H, Hu F-Q. Preparation and pharmacodynamics of low-molecular-weight chitosan nanoparticles containing insulin. Carbohydr Polym. (2009) 76(3): 368-73.

2. Mitra R. Adverse effects of corticosteroids on bone metabolism: areview. PM\&R. (2011) 3(5): 466-71.

3. Aslan M, Simsek G, Yildirim U. Effects of short-term treatment with systemic prednisone on bone healing: an experimental study in rats. Dent Traumatol. (2005) 21(4): 222-5.

4. Gonda T, MacEntee MI, Kiyak HA, Persson GR, Persson RE, Wyatt C. Predictors of multiple tooth loss among socioculturally diverse elderly subjects. Int $\mathrm{J}$ Prosthodont. (2013) 26(2):127-34.

5. Cohen N, Cohen-Lévy J. Healing processes following tooth extraction in orthodontic cases. J Dentofac Anomalies Orthod. (2014) 17(3): 304-25.

6. Vieira AE, Repeke CE, Junior S de BF, Colavite PM, Biguetti CC, Oliveira RC, et al. Intramembranous bone healing process subsequent to tooth extraction in mice: micro-computed tomography, histomorphometric and molecular characterization. PLoS One. (2015) 10(5):1-22.

7. Sahu PK, Giri DD, Singh R, Pandey P, Gupta S, Shrivastava AK, et al. Therapeutic and Medicinal Uses of Aloe vera: A Review. Pharmacol Pharm. (2013) 4(08): 599-610.

8. Arijani E, Khoswanto C. The use of $90 \%$ Aloe vera freeze drying as the modulator of collagen density in extraction socket of incicivus Cavia cobaya. Dent J (Majalah Kedokt Gigi). (2008) 41(2): 74-6. 
9. Das DS, Subramaniam DA, Gill DM, Chowdhery DA, Subramaniam DT. Versatility of Aloe Vera in DentistryA review. IOSR J Dent Med Sci. (2014) 13(10): 98-102.

10. Jeanne D, Godoy D, Chokboribal J, Pauwels R, Banlunara W, Sangvanich P, et al. Acemannan increased bone surface, bone volume and bone density in a calvarial defect model in skeletally-mature rats. J Dent Sci. (2018) 7(6): 124-31.

11. Hebeish A, El-Rafie MH, El-Sheikh MA, Seleem AA, El-Naggar ME. Antimicrobial wound dressing and antiinflammatory efficacy of silver nanoparticles. Int J Biol Macromol. (2014) 65: 509-15.

12. Liu X, Lee P, Ho C, Lui VCH, Chen Y, Che C, et al. Silver nanoparticles mediate differential responses in keratinocytes and fibroblasts during skin wound healing. ChemMedChem. (2010) 5(3): 468-75.

13. Zhang R, Lee P, Lui VCH, Chen Y, Liu X, Lok CN, et al. Silver nanoparticles promote osteogenesis of mesenchymal stem cells and improve bone fracture healing in osteogenesis mechanism mouse model. Nanomedicine Nanotechnology, Biol Med. (2015) 11(8): 1949-59.

14. Li J, Wang X, Zhou C, Liu L, Wu Y, Wang D, et al. Perioperative glucocorticosteroid treatment delays early healing of a mandible wound by inhibiting osteogenic differentiation. Injury. (2012) 43(8): 1284-9.

15. Lelovas PP, Xanthos TT, Thoma SE, Lyritis GP and Dontas IA. the laboratory rat as an animal model for osteoporosis research. Comp Med. (2008) 58(5): 424-30.

16. Lee C, Meisel D. Adsorption and Surface-Enhanced Raman of Dyes on Silver and Gold Sols'. J Phys Chem. (1982) 17(86): 3391-5.

17. Feldman AT, Wolfe D. Tissue processing and hematoxylin and eosin staining. In: Histopathology. Humana Press, New York, NY.2014) ;) pp; 31-43.

18. Hassumi JS, Mulinari-Santos G, FABRIS $\mathrm{AL}$ da S, JACOB RGM, Goncalves A, Rossi AC, et al. Alveolar bone healing in rats: micro-CT, immunohistochemical and molecular analysis. J Appl Oral Sci. (2018) 26: 1-12.

19. Samir SM, Malek HA. Effect of cannabinoid receptors 1 modulation on osteoporosis in a rat model of different ages. J Physiol Pharmacol. (2014) 65(5): 687-94.

20. Hars E, Massler M. Effects of fluorides, cortico-steroids and tetracyclines on extraction wound healing in rats. Acta Odontol Scand. (1972) 30(5-6): 511-22.

21. Gilley RS, Wallace LJ, Bourgeault CA, Kidder LS, Bechtold JE. OP-1 augments glucocorticoid-inhibited fracture healing in a rat fracture model. Clin Orthop Relat Res. (2009) 467(12): 3104-12.
22. Rollo JMDA, Boffa RS, Cesar R, Schwab DC, Leivas TP Assessment of trabecular bones microarchitectures and crystal structure of hydroxyapatite in bone osteoporosis with application of the Rietveld method . Procedia Eng. (2015) 110: 8-14.

23. Shen $Y$, Zhang Z-M, Jiang S-D, Jiang L-S, Dai L-Y. Postmenopausal women with osteoarthritis and osteoporosis show different ultrastructural characteristics of trabecular bone of the femoral head. BMC Musculoskelet Disord. (2009) 10(1): 35-46.

24. Martinelli Jr CE, Moreira AC. Relation between growth hormone and cortisolspontaneous secretion in children. Clin Endocrinol. (1994) 41(1): 117-21.

25. Kim H-J, Zhao H, Kitaura H, Bhattacharyya S, Brewer JA, Muglia LJ, et al. Glucocorticoids suppress bone formation via the osteoclast. J Clin Invest. (2006) 116(8): 2152-60.

26. Huybers S, Naber THJ, Bindels RJ, Hoenderop JGJ. Prednisolone-induced $\mathrm{Ca} 2+$ malabsorption is caused by diminished expression of the epithelial Ca2+ channel TRPV6. Am J Physiol Liver Physiol. (2007) 292(1): 92-7.

27. Roschger P, Matsuo K, Misof BM, Tesch W, Jochum $\mathrm{W}$, Wagner EF, et al. Normal mineralization and nanostructure of sclerotic bone in mice overexpressing Fra-1. Bone. (2004) 34(5): 776-82.

28. Boonyagul S, BanlunaraW, SangvanichP, Thunyakitpisal P. Effect of acemannan, an extracted polysaccharide from Aloe vera, on BMSCs proliferation, differentiation, extracellular matrix synthesis, mineralization, and bone formation in a tooth extraction model. Odontology. (2014) 102(2): 310-7.

29. Al-Hijazi AY, Al-Mahammadawy A, Altememe EI. Expression of BMP7 in bone tissue treated with Aloe vera. Int Res J Nat Sci. (2015) 3(2): 39-48.

30. Jansisyanont $\mathrm{P}$, Tiyapongprapan $\mathrm{S}$, Chuenchompoonut V, Sangvanich P, Thunyakitpisal P. The effect of acemannan sponges in post-extraction socket healing: A randomized trial. J Oral Maxillofac Surgery, Med Pathol. (2016) 28(2): 105-10.

31. Andre-Frei V, Chevallay B, Orly I, Boudeulle M, Huc A, Herbage D. Acellular mineral deposition in collagenbased biomaterials incubated in cell culture media. Calcif Tissue Int. (2000) 66(3): 204-11.

32. Beniash E. Biominerals - hierarchical nanocomposites: the example of bone. Wiley Interdiscip Rev Nanomedicine Nanobiotechnology. (2011) 3(1): 47-69.

33. Georgiadis M, Müller R, Schneider P. Techniques to assess bone ultrastructure organization: orientation and arrangement of mineralized collagen fibrils. J R Soc Interface. (2016) 13(119): 20160088-113. 
34. Ng F, Boucher S, Koh S, Sastry KSR, Chase L, Lakshmipathy $\mathrm{U}$, et al. PDGF, TGF- $\beta$, and FGF signaling is important for differentiation and growth of mesenchymal stem cells (MSCs): transcriptional profiling can identify markers and signaling pathways important in differentiation of MSCs into adipogenic, chondrogenic and osteogenic lineages. Blood. (2008) 112(2): 295-307.

35. Solchaga LA, Penick K, Goldberg VM, Caplan AI, Welter JF. Fibroblast growth factor-2 enhances proliferation and delays loss of chondrogenic potential in human adult bone -marrow-derived mesenchymal stem cells. Tissue Eng Part A. (2009) 16(3):1009-19.
36. Jung S-R, Song N-J, Yang DK, Cho Y-J, Kim B-J, Hong J-W, et al. Silk proteins stimulate osteoblast differentiation by suppressing the Notch signaling pathway in mesenchymal stem cells. Nutr Res. (2013) 33(2):162-70.

37. Keleştemur S, Kilic E, Uslu Ü, Cumbul A, Ugur M, Akman S, et al. Wound healing properties of modified silver nanoparticles and their distribution in mouse organs after topical application. Nano Biomed Eng. (2012) 4(4): 170-76.

38. Polívková, M., Hubáček, T., Staszek, M., Švorčík, V., \& Siegel, J, Siegel J. Antimicrobial treatment of polymeric medical devices by silver nanomaterials 18(2)419-42. 


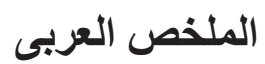

\section{تأثثير الإستخدام الموضعي لجل الألوفيرا مقارنة بجزيئات الفضة النانوية على إلتئام مكان

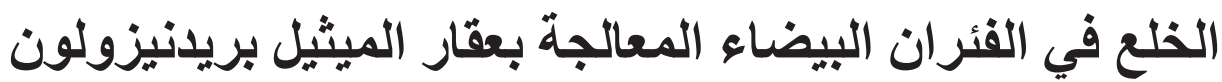 \\ أسماء شاكر القصاص'، هبه محمد الطوخي'، أمل محمد عزت'، جيهان شحاته حسن' جئ}

\section{قسم بيولوجيا الفم ـ كلية طب الاسنان - 'جامعة طنطا ـ بجامعة 7 أكتوبر}

مقدمة: يتسبب عقار الميثيل بريدنيزولون في تأخير شفاء النسيج و هناك بيانات محدودة لتأثير جل الصبار وجل جزيئات

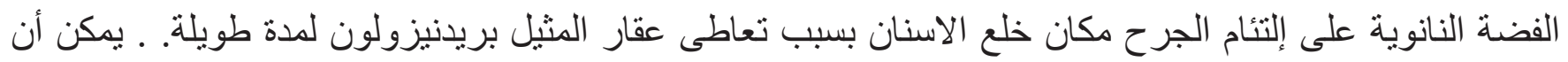

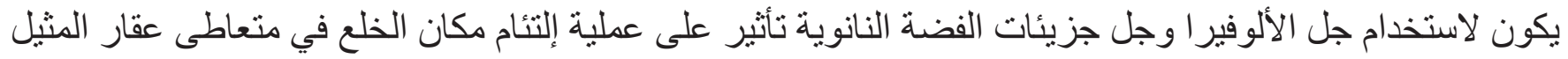
بريدنيزولون لمدة طويلة. المواد والطرق المستخدمة: أجريت هذه الدراسة على إثنان وثثلاثثن فأرًا قسمت إلى ثلاث مجموعات. المجموعة

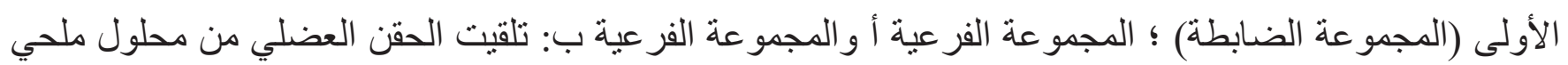

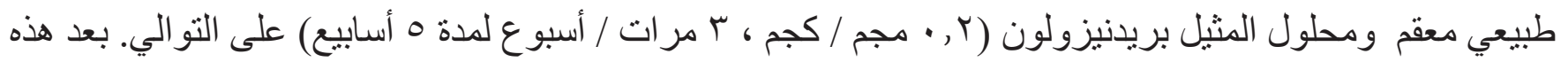

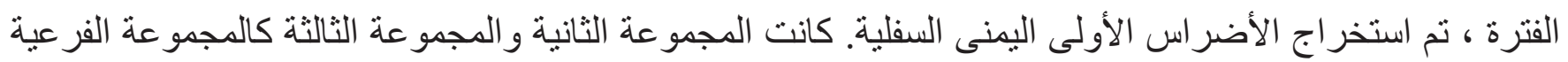

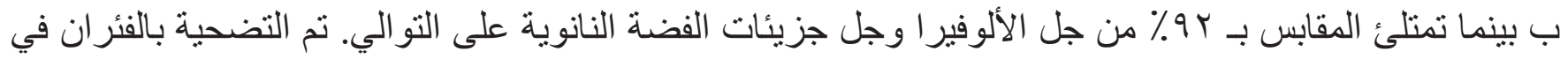

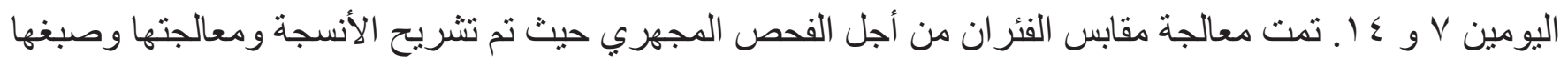
بصبغة الهيماتو كسيلين و الايوسين وفحصها بالميكروسكوب الضونئي. ثم تم فحص باقي العينات بإستخدام الميكروسكوب الماسح الإكتروني النسيجي. ونم عمل تحليل القياس النسيجي لقياس النسبة المئوية لكمية العظام التي تكونت مكان الخلع

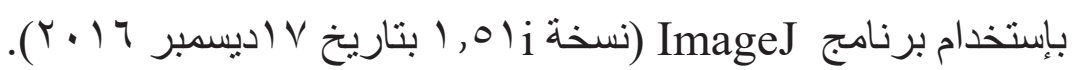

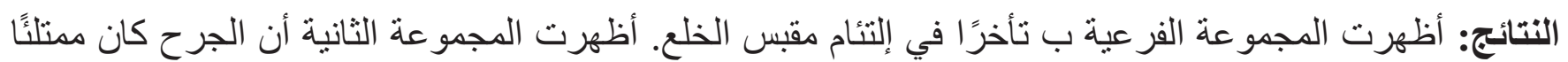

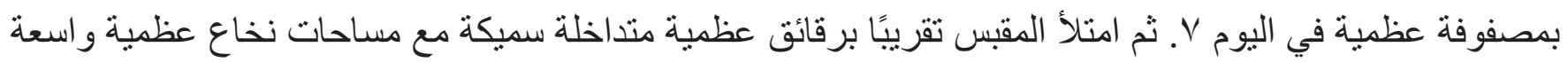
في اليوم ع ا ـ كثفت المجموعة الثالثة عن أن الجر ح ملئ برقائق عظمية رفيعة منشابكة مع كمية قليلة من النسيج الضام في اليوم У. في اليوم § ا ، أصبح مقبس الخلع طمس تقريبًا بعظام ناضجة مليئة بنظام هافيرجين التى تحيط منطقة صغيرة من نخاع العظام. الاستنتاج: تسبب عقار المثيل بريدنيزولون تأخير عملية التئام المقبس بينما أدى الاستخدام الموضعي لجل الصبار وجل جزيئات الفضة النانوية إلى تحسين شفاء الجروح مكان خلع الاسنان في متعاطى عقار المثيل بريدنيزولون لمدة طويلة. 